\title{
The Journal of Orthopaedics and Traumatology: reflecting Italian orthopaedics worldwide
}

\author{
M. d'Imporzano
}

Published online: 24 September 2010

(c) The Author(s) 2010. This article is published with open access at Springerlink.com

The Journal of Orthopaedics and Traumatology, official journal of the Italian Society of Orthopaedics and Traumatology (SIOT), has established a solid reputation not only in Italy but also on the international scientific scene. As a result of many years of commitment, enthusiasm and energy on the part of its Founding Editor, Prof. Francesco Pipino, and of the efforts of a dedicated Editorial Board and a leading international publisher, it is now included in PubMed/Medline and read in thousands of hospitals and academic institutions worldwide.

At the most recent Editorial Board meeting we were pleased to see the fruits of our recent publishing activities. The strategy of adopting Open Access has allowed the journal to be included in PubMed Central, which has considerably increased the visibility of its valuable content.

This editorial strategy and the innovative publishing model, together with a selective peer review process that has led to a rejection rate of $60 \%$ (in line with that of other leading medical journals), have contributed to the journal's growing international recognition, which is reflected by the constant increase in the number of full-text downloads. With its already consolidated European reputation, the journal is now beginning to be more widely read in the emerging countries of Asia as well as in the more traditionally and scientifically recognised area of North America. Furthermore, in 2010 there has been a $57 \%$ increase in

\footnotetext{
M. d'Imporzano ( $\square)$
}

Department of Orthopaedics and Traumatology,

3rd Division of Orthopaedics and Traumatology,

Azienda Ospedaliera Istituto Ortopedico "G. Pini",

Piazza Cardinale Andrea Ferrari 1, 20122 Milan, Italy

e-mail: dimpomarco@live.it the number of submissions (more than $70 \%$ of which come from overseas), and a $30 \%$ reduction in the time required for peer reviewing. The average time from the acceptance of a manuscript to its online publication is about 3 weeks, which ensures timely publication and therefore constant updates for the reader.

However, although all of us were delighted to see the journal's inclusion in Medline, the consequent increase in the number of submissions has required a new distribution of management responsibilities.

I feel extremely honoured to have been appointed as Editor-in-Chief, but we all need to express our warmest and heartfelt thanks to Prof. Pipino, who founded the journal and edited it for so many years with that passion, competence and judgement that we all acknowledge: a great maestro, a great Editor-in-Chief, and a great friend.

We are currently considering the possibility of appointing Consulting Editors for individual subject areas in order to base the peer review on specific competencies. Consulting Editors would also be responsible for promoting international cooperation with foreign scientific societies, journals covering related disciplines, and authoritative contributors.

Each Consulting Editor would be assisted by a group of collaborators and, in this regard, I hope that young orthopaedists will support them.

As I had the opportunity to underline during the opening session of the last national SIOT Congress in Milan, I believe that Italy has the expertise and excellence to carry out clinical studies and trials of the highest scientific value: now we have also an excellent editorial product that can circulate them worldwide.

The next challenge will be inclusion in Thomson Reuters and the assignment of an impact factor. 
I am aware that these are ambitious objectives, but I trust that cooperation among SIOT members, authors, reviewers and editors will grant us excellence and increased international recognition.
Open Access This article is distributed under the terms of the Creative Commons Attribution Noncommercial License which permits any noncommercial use, distribution, and reproduction in any medium, provided the original author(s) and source are credited. 